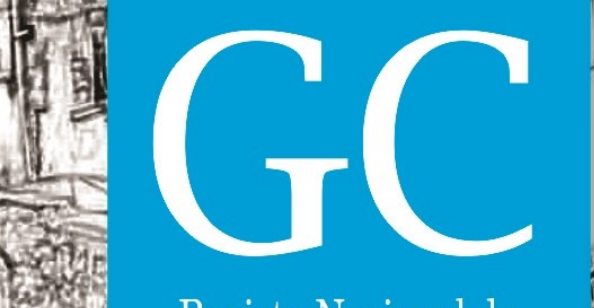

Revista Nacional de

Gerenciamento de Cidades

\title{
O morar informal e invisível: Habitações Coletivas Precárias de Aluguel da área central de João Pessoa-PB e sua condição de invisibilidade
}

The informal and invisible inhabit: Collective Precarious Rental Houses of the downtown of João Pessoa-PB and its invisibility condition

El hábitat informal e invisible: Viviendas colectivas precarias de alquiler en la zona central de João Pessoa-PB y su condición de invisibilidad

\section{Camila Coelho Silva}

Professora Mestre, IF SERTÃO-PE - Campus Serra Talhada, Brasil. camila.coelho@ifsertao-pe.edu.br 


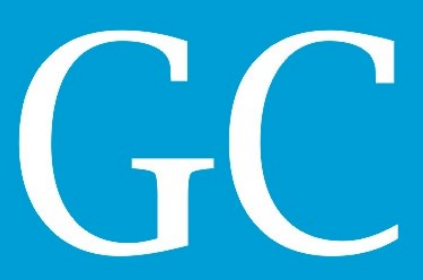

Revista Nacional de

\section{RESUMO}

O processo de esvaziamento, desvalorização e degradação das áreas centrais traz como revés a atração de uma nova população moradora empobrecida e novas formas de ocupação desses espaços. Um dos principais fenômenos resultantes, e questão expressiva desde o século XIX, é o surgimento e multiplicação de habitações coletivas precárias de aluguel (HCPAs) na forma de vilas e cortiços. Tais formas de moradia, por diversos fatores, tornam-se invisíveis perante olhares dos citadinos, de estudiosos e do poder público, ocultando a realidade do morar informal nos centros antigos. Neste sentido, este artigo propõe um estudo de caso das HCPAs da área central da cidade de João Pessoa-PB, mais precisamente do bairro Varadouro, com objetivo principal de caracterizar sua condição de invisibilidade, no anseio de compreender sua lógica de produção/reprodução, bem como de prover uma base científica para a formulação de políticas públicas de enfrentamento da necessidade de oferta qualificada do solo urbano para a população pobre. A partir da construção do referencial teórico-conceitual e das pesquisas documental e empírica, foi possível constatar que a condição de invisibilização das HCPAs e de seus moradores não deve ser elucidada apenas através de seu aspecto na paisagem construída da cidade, mas também por sua forma de acesso e pelas características sociais e de vida. Percebe-se ainda a ausência da gestão pública perante o quadro de ilegalidade e descaso com a qualidade habitacional desta produção, bem como a inexistência de política urbana e habitacional eficiente que promova de maneira adequada o reaproveitamento das áreas centrais.

PALAVRAS-CHAVE: Habitações Coletivas Precárias de Aluguel. Área central. Invisibilidade.

\section{ABSTRACT}

The process of emptying, devaluation and degradation of central areas has as setback the attraction of a new resident impoverished population and new forms of occupation of these spaces. One of the main resultant phenomena, and significant issue since the XIX century, is the emergence and multiplication of collective precarious rental houses (HCPAs) as vilas and cortiços. Such forms of housing, by several factors, become invisible before eyes of citizens, scholars and the public power, hiding the reality of the informal inhabit in downtowns. Thus, this article proposes a case study of HCPAs of the central area of the city João Pessoa-PB, more precisely in Varadouro neighborhood, with main objective to characterize its condition of invisibility, with desire to understand its logic of production/reproduction, as well as to provide a scientific basis for the formulation of public policies of facing the need for qualified offer of urban land for the poor population. From the construction of the theoretical and conceptual framework and documentary and empirical researches, it was found that the invisibility condition of HCPAs and its residents should not be elucidated only through its appearance in the built landscape of the city, but also for its form access and the social and life characteristics. It is noticed also the absence of public administration before the illegal frame and neglect of the housing quality of this production, well as the lack of efficient urban and housing policy that promotes adequately the reutilizacion of the central areas.

KEYWORDS: Collective Precarious Rental Houses. Downtown. Invisibility.

\section{RESUMEN}

El proceso de vaciamiento, devaluación y degradación de las áreas centrales trae como revés la atracción de una nueva población residente empobrecida y nuevas formas de ocupación de estos espacios. Uno de los principales fenómenos resultantes, y cuestión significativa desde el siglo XIX, es la aparición y multiplicación de viviendas colectivas precarias de alquiler (HCPAs) en forma de villas e conventillos. Tales formas de vivienda, por varios factores, vuelven invisibles delante de los ojos de los ciudadanos, académicos y autoridades públicas, ocultando la realidad del hábitat informal en los viejos centros. En este sentido, este artículo propone un estudio de caso de las HCPAs de la zona central de la ciudad de João Pessoa-PB, más precisamente en el barrio Varadouro, con el objetivo principal de caracterizar su condición de invisibilidad, en el ansia de entender su lógica de producción/reproducción, así como proporcionar una base científica para la formulación de políticas públicas para hacer frente a la necesidad de oferta calificada de suelo urbano para la población pobre. A partir de la construcción del marco teóricoconceptual y las investigaciones documental y empírica, se encontró que la condición de invisibilidad de las HCPAs y sus residentes no debe ser dilucidado sólo a través de su aparición en el paisaje construida de la ciudad, sino también por su forma acceso y las características sociales y de vida. Se observa también la ausencia de la administración pública delante de la trama ilegal y la negligencia de la calidad de la vivienda de esta producción, bien como la ausencia de política urbana y habitacional eficiente que promueva adecuadamente la reutilización de las áreas centrales.

PALABRAS-CLAVE: Viviendas colectivas precarias de alquiler. Área Central. Invisibilidad. 


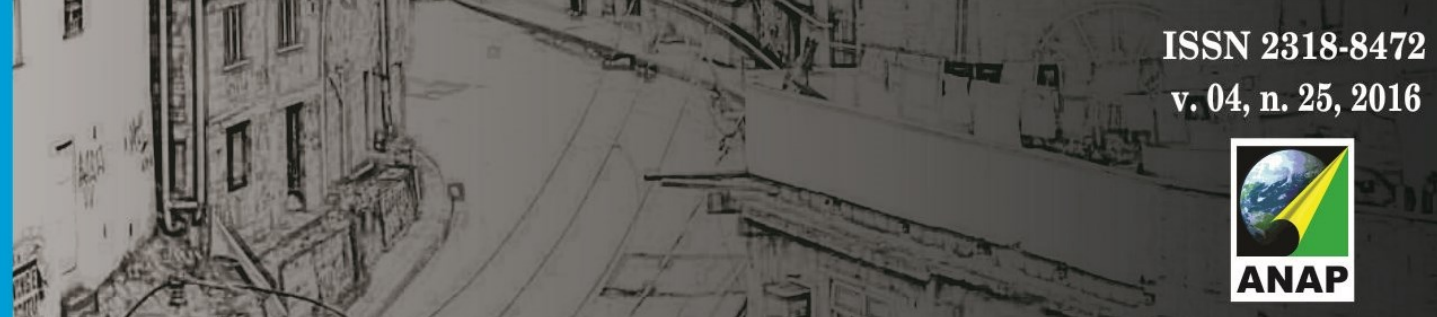

Revista Nacional de Gerenciamento de Cidades

sentido de afirmarem a não vitalidade, o abandono ou até mesmo a morte dos "centros históricos". Em contraponto a esta percepção, este artigo apresenta parte dos resultados de pesquisa no âmbito do Programa de Pós-Graduação em Arquitetura e Urbanismo da Universidade Federal da Paraíba (PPGAU/UFPB) desenvolvida entre 2013 e 2015 (SILVA, 2015). Chama atenção para a (r)esistência de invisíveis moradias coletivas existentes em parte do centro histórico de João Pessoa, mais precisamente na delimitação do bairro Varadouro, local originalmente marcado por atividades de comércio, serviços e habitação desde os primórdios da constituição e crescimento da cidade.

Atenta-se ainda para a ausência do Estado e a inexistência de política urbana e habitacional eficiente que promova de maneira adequada o reaproveitamento de tais áreas. Como Alfonsin e Fernandes (2003, p.X) relatam, a legislação urbanística de nosso país tem apresentado o papel de "dar suporte aos, montar o palco para, e ser coadjuvante dos processos de apropriação privada de investimentos públicos pelas parcelas mais abastadas das populações urbanas". Em paralelo, a população de baixa renda é relegada, e as áreas centrais esquecidas pelo poder público apesar das vantagens já citadas.

Impossibilitados de possuírem casa própria ou de alugarem moradias melhores devido aos altos valores de aluguéis, ou pela necessidade de residirem próximos ao local de trabalho pelo custo da mobilidade urbana, ou ainda combinando as alternativas citadas, os indivíduos de baixa renda não têm outra opção senão o aluguel de habitações coletivas, geralmente precárias, insalubres e sem o mínimo de condições necessárias à habitabilidade.

Assim, rendendo-se à lógica da necessidade (de morar), as camadas de baixa renda que ainda podem pagar a locação de pequenos e precários cômodos passaram a sustentar este mercado de regras próprias e em franca expansão no Brasil. Apesar da inadequação das habitações e das dificuldades enfrentadas devido à condição de coletividade, bem como das incertezas que - mercado informal oferece, as habitações coletivas de aluguel fazem pulsar vida, imperceptíveis por trás das fachadas ecléticas ou de grandes portões descaracterizadores dos antigos casarões. Vale destacar que não nos referimos aqui à qualidade de vida, mas simplesmente à sua existência.

Nesse contexto, sente-se a necessidade de apreender o processo de invisibilização das habitações coletivas de aluguel nas áreas centrais das cidades contemporâneas partindo do caso da cidade de João Pessoa. Seu entendimento torna-se fundamental para compreensão de sua lógica de produção/reprodução e para a provisão de uma base científica para a formulação de políticas públicas de enfrentamento da necessidade de oferta qualificada do solo urbano para a população pobre. 
Revista Nacional de

\section{OBJETIVOS E RECORTE DE ESTUDO}

A partir da discussão supracitada, definiu-se como objetivo geral do artigo caracterizar a condição de invisibilidade das habitações coletivas precárias de aluguel (HCPAs) do bairro Varadouro, João Pessoa-PB. Como objetivos específicos, buscou-se:

a) Conceituar e caracterizar as HCPAs de modo geral;

b) Identificar as características peculiares da moradia na área central;

c) Identificar as HCPAs do bairro Varadouro.

Localizado na área central da cidade de João Pessoa, totalmente inserido na delimitação do centro histórico pelo IPHAEP - Instituto do Patrimônio Histórico e Artístico do Estado da Paraíba e tendo parte de suas quadras também inseridas na delimitação do IPHAN - Instituto do Patrimônio Histórico e Artístico Nacional, o bairro do Varadouro (figura 01) foi escolhido como recorte de estudo por diversos fatores.

Figura 01: Indicação do recorte de estudo - bairro Varadouro - dentre as delimitações do centro histórico da cidade de João Pessoa definidas pelo IPHAN e IPHAEP.

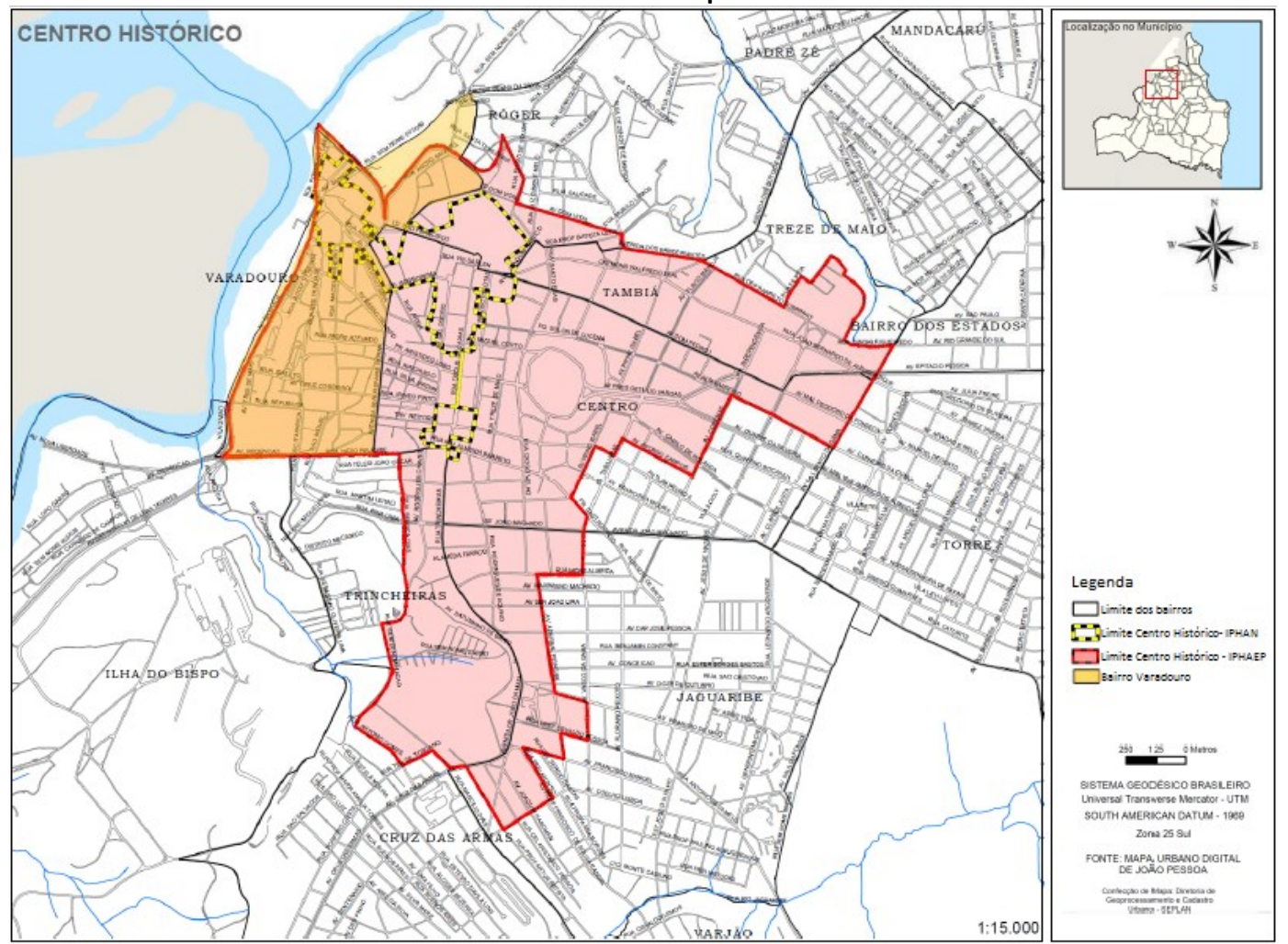

Fonte: Mapa urbano digital de João Pessoa, 2014, editado por Camila Coelho.

Ele é indicado pela literatura da história da cidade de João Pessoa bem como por historiadores como sendo um dos bairros mais antigos onde se desenvolveu um misto de atividades e residências desde os primórdios desta cidade, e onde se estabeleceram algumas das ruas 
(2003), Bonduki (2004), Piccini (2004), Kowarick (2007; 2009), e nas obras internacionais de Engels (2008 [1845]), David Harvey (1989), Henri Lefebvre (2001), Mike Davis (2006). Na abordagem sobre a condição de invisibilidade, apenas foram identificados os trabalhos de Alfonsin (2000) e Paris (2013), instigando a necessidade da discussão a que se propõe o artigo.

\section{2a Etapa: Pesquisa documental}

Coletaram-se informações em diversas instituições sobre a existência das habitações coletivas de aluguel e a dinâmica do mercado imobiliário no bairro do Varadouro. O primeiro órgão consultado foi a Prefeitura Municipal de João Pessoa - PMJP, através da solicitação de mapas do bairro Varadouro e do Cadastro de Vilas, fornecidos em julho de 2014 pela Diretoria de Geoprocessamento e Cadastro Urbano da Secretaria de Planejamento - SEPLAN. Foi consultado ainda o Instituto Brasileiro de Geografia e Estatística - IBGE, com a finalidade de ter acesso a dados oficiais quantitativos referentes às habitações do bairro e de seus residentes.

Na busca de informações sobre o mercado imobiliário no bairro do Varadouro, buscaram-se os dados de demanda imobiliária e pesquisa de mercado oferecidos nos sites do Sindicato da Indústria da Construção Civil de João Pessoa - Sinduscon (dados de novembro de 2013 a junho de 2014) e do Conselho Regional de Corretores de Imóveis - CRECI (dados de janeiro a setembro de 2012).

Ainda foi consultada a legislação do município de João Pessoa, como Plano Diretor, Código de Obras e de Urbanismo, mas nenhum deles faz referência a qualquer tipo que seja de habitação coletiva precária de aluguel, corroborando com a condição de invisibilidade de tal forma de moradia.

\section{3a etapa: Pesquisa de campo e análise dos dados}

$\mathrm{Na}$ falta de um levantamento preciso e da caracterização das habitações coletivas de aluguel presentes na área central de João Pessoa, foi necessária a realização da pesquisa de campo para identificação de tais moradias. Todas as ruas e avenidas do bairro foram percorridas entre os meses de setembro e dezembro de 2014, período em que constatamos a existência de $\mathbf{4 3}$ HCPAs (figura 02), das quais 35 obteve-se acesso, representando $81,4 \%$ do total mapeado. 
consigo diferentes formas de apropriação e valorização do solo urbano, refletindo em especial nas áreas centrais das cidades.

Concomitantes ao congestionamento dos centros devido à intensidade de seus comércios e serviços surgem outros lugares mais atraentes para se viver. As atividades ditas "nobres" (VARGAS; CASTILHO, 2009) e a população mais abastada migram para estes novos locais e são substituídas por atividades menos rentáveis, por vezes informais, e até ilegais, exercidas por moradores/usuários de baixo ou nenhum poder aquisitivo, estes se mantendo em condições de vasta precariedade; assim, degradaram-se os espaços públicos e o acervo edificado, proliferaram as habitações coletivas precárias como cortiços e vilas particulares, e foram gerados vazios urbanos no coração das cidades (ROLNIK; BOTLER, 2004; BONDUKI, 2004).

As principais formas de habitações coletivas e que ainda se fazem presentes nas áreas centrais de boa parte das cidades brasileiras são os cortiços e vilas populares. Inúmeros fatores propiciaram a multiplicação destas moradias: a demanda por habitações de baixo custo para os trabalhadores, a restrita disponibilidade de imóveis para atendê-la, os aluguéis exorbitantes, a impossibilidade de se obter a casa própria devido aos baixos salários ou à ausência deles, e a possibilidade de os proprietários e arrendatários de terrenos e imóveis lucrarem com sua produção.

A terminologia mais recente relativa aos cortiços é "Habitação Coletiva Precária de Aluguel" ou HCPA (PICCINI, 2004), que classifica tais habitações segundo fatores definidos pela Lei Moura ${ }^{2}$ Lei Municipal no 10.928 de 1991, única lei alusiva aos cortiços. Com esta definição, e, a partir da análise de diversas conceituações, percebe-se que muitos dos atributos referentes aos cortiços também podem ser constatados nas vilas. Se a única diferença claramente identificada entre as tipologias é a questão da coletivização ou não das áreas molhadas (banheiros, áreas de serviço e/ou cozinha), o conceito definido pela Lei Moura permite inserir a vila na mesma definição.

Deste modo, os cortiços e vilas são retratados aqui com o termo Habitação Coletiva Precária de Aluguel ou HCPA, referente à unidade usada como moradia multifamiliar e acessada através da locação ou sublocação, apresentando, total ou parcialmente, as seguintes características:

a) Ser constituída por uma ou mais edificações construídas em lote urbano;

b) Ser subdividida em mais de uma unidade habitacional;

c) Utilizar o mesmo ambiente para exercer diversas funções (estudar, dormir, cozinhar, fazer refeições, trabalhar, etc.);

d) Ter acesso comum dos espaços não edificados;

\footnotetext{
${ }^{2}$ A Lei Moura nasceu da necessidade de regular as condições de habitação e as questões que envolviam o pagamento de aluguéis dos mais de 90 mil cortiços paulistas. Estabelece critérios de habitabilidade, salubridade, higiene e segurança para os cortiços, bem como regula aspectos edilícios, condições mínimas de ventilação, pé direito mínimo, etc.
} 


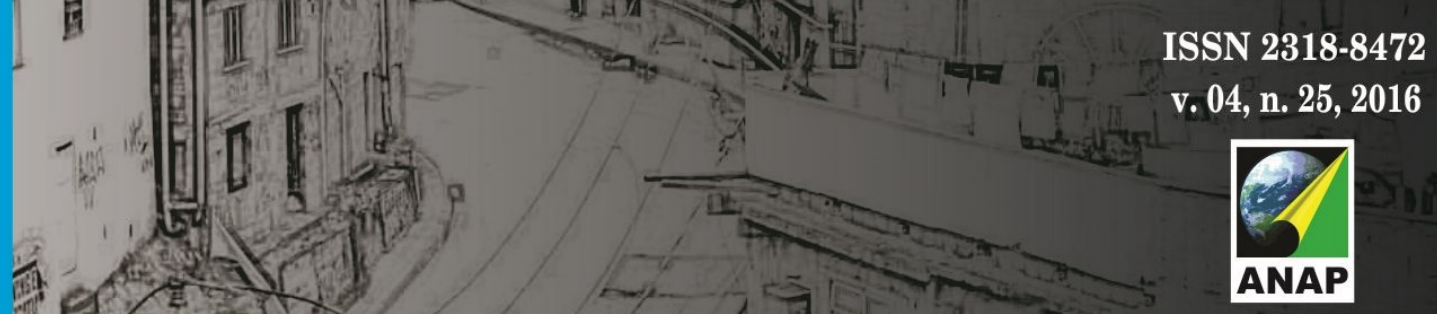

Revista Nacional de Gerenciamento de Cidades

e) Apresentar uso comum das instalações hidráulicas e sanitárias, sejam os banheiros, cozinhas e/ou tanques;

f) Oferecer infraestrutura, no geral, precária, causando riscos à saúde ou à vida (ventilação e iluminação naturais inadequadas, umidade excessiva, infiltrações, instalações elétrica e hidráulica em más condições, etc.);

g) Apresentar superlotação de pessoas.

Mesmo com a precariedade, a insalubridade e a falta de habitabilidade, as habitações coletivas de aluguel localizadas nas áreas centrais das cidades ainda são boas opções de moradia para muitos, se comparadas às habitações nas periferias, rejeitada pela falta de infraestrutura, mas sobretudo pela distância. É nesse contexto que, com o passar dos anos, os cortiços e vilas foram se firmando como alternativa de moradia, ocupando principalmente as zonas centrais das cidades, muitas vezes invisíveis ou ignoradas aos olhos dos transeuntes e principalmente do poder público. Com relação às intervenções nas áreas centrais, as políticas e programas frequentemente são acompanhadas da valorização da área e da expulsão das famílias pobres, não havendo interesse para se melhorar e manter as habitações coletivas ativas; ignoram-nas, e deixam passar a oportunidade de utilizá-las como uma das soluções para manutenção da vitalidade dessa região.

Assim sendo, os cortiços e vilas populares resistem, invisíveis, e seus moradores (sobre)vivem sem esperanças de melhorias nas habitações e, por conseguinte, de vida, mas, ainda assim, preservam a vida (ou sobrevida) das áreas centrais fora do horário comercial, indo contra o discurso de morte dos centros urbanos.

Estando cientes da conjuntura e da problemática em que o fenômeno dos cortiços e vilas se insere, cabe discutir a sua condição de invisibilidade, fator preponderante para inserção, (r)existência e manutenção de tais moradias nas áreas centrais, principalmente no centro de João Pessoa.

\section{A condição de Invisibilidade das HCPAs inseridas na área central do Varadouro}

Quando a discussão sobre a questão da moradia da população de baixa renda brasileira é instigada, é comum se pensar nos barracos construídos nos morros ou nas margens dos rios, ou nas favelas, formas explícitas de habitação ilegal marcantes na paisagem urbana do país.

Neste contexto, as habitações coletivas de aluguel, consolidadas em especial nas áreas centrais urbanas, em edificações antigas subdividas em diversos cômodos para locação ou ainda por casas de condições precárias construídas para o mesmo fim, acabam sendo mimetizadas pelo tecido urbano, pelo mercado imobiliário formal e, consequentemente, pelo imaginário coletivo. Como bem discorrem Kohara e Piccini (1999, p.07), "Mesmo estando a maior concentração dos imóveis encortiçados situados nos bairros centrais da cidade, é uma realidade pouco visível, não se constituindo em uma paisagem, mas escondendo-se entre as edificações que marcaram o desenvolvimento dela". 
Por serem edificações unifamiliares na maioria dos casos, tais habitações passam despercebidas na paisagem urbana, tendo em suas fachadas um bom "disfarce" para a precariedade, miséria e inadequação habitacional a que estão sujeitos seus moradores (figuras 03 a 06). Em contraponto, tornam-se visíveis quando há interesse do capital imobiliário na área onde estão inseridas, e seus moradores são os primeiros a serem remanejados ou até expulsos, como nos mostra a história da habitação popular nas áreas centrais urbanas.

Figuras 03 a 06: Exemplares de HCPAs localizadas em diversas ruas do bairro Varadouro invisibilizadas devido à aparência de habitação unifamiliar das fachadas principais de seus edifícios.
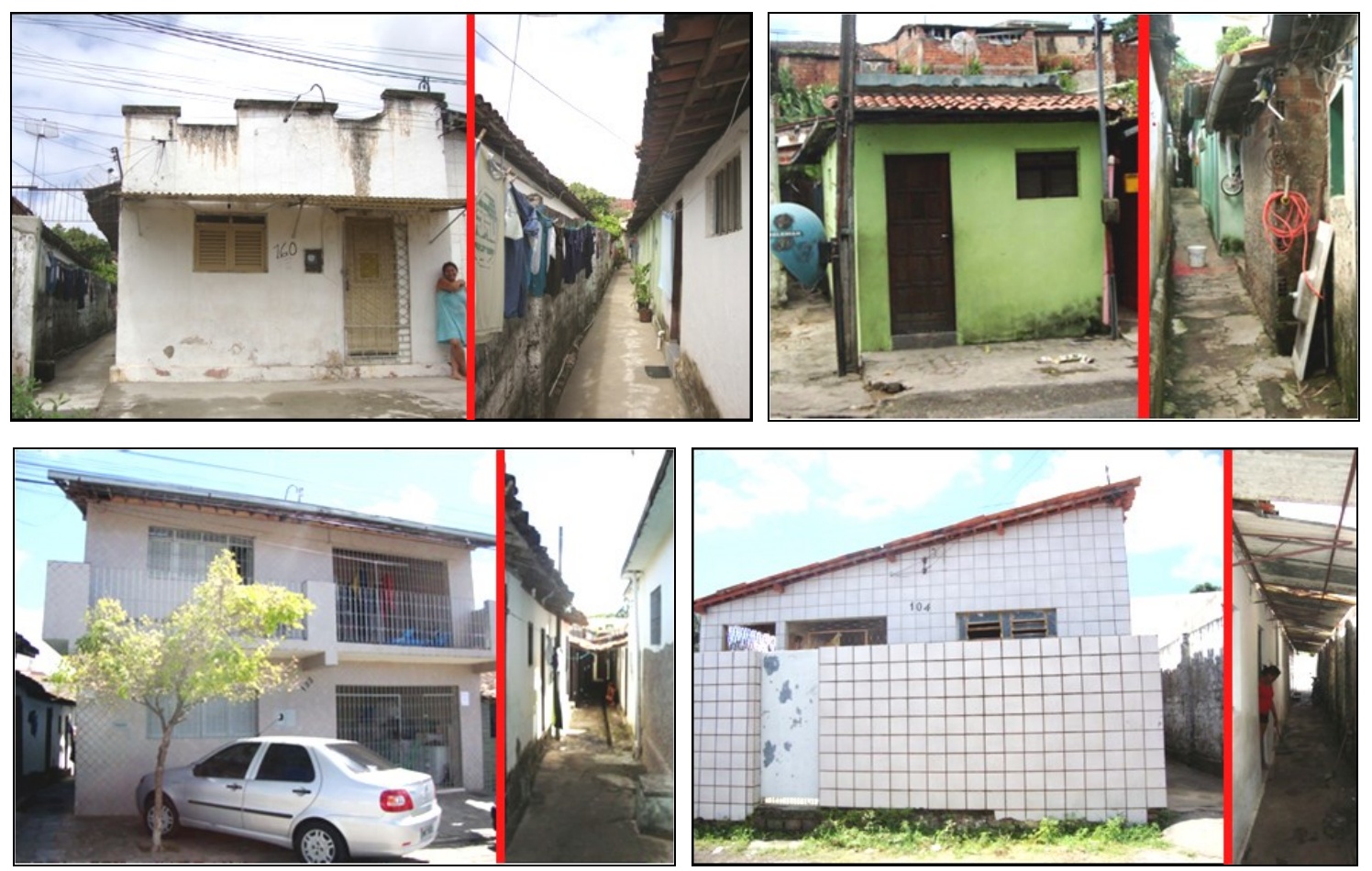

Fonte: Acervo pessoal, 2012/2014.

O processo de invisibilidade ou "invisibilização" de habitações coletivas populares como vilas e cortiços tem início, segundo Alfonsin (2000), em fins do século XIX e início do século XX, quando se convivia com a pobreza disfarçando sua presença, escondendo-a, invisibilizando-a. A autora relaciona o processo de invisibilização da população pobre e, consequentemente, de suas precárias condições de moradia, ao plano das representações que compõem o imaginário de uma cidade, uma vez que estas possuem a "capacidade de reapresentar o real e de articular uma relação ambígua entre ausência e presença" (PESAVENTO, 1998, p.02 apud ALFONSIN, 2000, p.49). Assim, as representações se colocam "no lugar" do real, substituindo-o, e possibilitando, no plano do imaginário, uma cidade sem a presença dos pobres.

A princípio, nessa época, a invisibilidade das habitações populares era determinada pelo poder público: 
Tanto a tipologia do cortiço, como a população pobre que ia residir nos nascentes "arraiais", em "casinhas" de porta e janela, inicia uma trajetória de irregularidade, clandestinidade e exclusão em relação aos equipamentos e serviços urbanos que a municipalidade oferece, mas, sem que o declare, não oferece ao conjunto da população. (ALFONSIN, 2000, p. 53)

A exclusão e invisibilização de tais formas de moradia se concretizaram até mesmo na fala de autores e viajantes do período, que ignoravam a população de baixa renda e suas condições de vida em detrimento da descrição da vida da elite das cidades brasileiras.

Foi nesse contexto que as habitações coletivas precárias de aluguel se fizeram presentes nas áreas centrais das urbes, em segundo plano, e resistem ao tempo com praticamente o mesmo lema: poucos as veem, quase ninguém as descreve, e, ainda, escassas são as ações por parte do poder público no sentido de proporcionar melhorias aos seus moradores. "Éloigner pour oublier, éloigner pour ne pas voir, éloigner pour cacher..." ${ }^{3}$ (PARIS, 2013, p.09): esta estratégia é o cerne de muitos problemas da gestão urbana no que diz respeito às habitações populares. Edésio Fernandes (2003, p.178) explica:

[...] deve-se ressaltar o papel das leis elitistas e socialmente inadequadas, que têm historicamente desconsiderado as realidades dos processos socioeconômicos de produção da moradia, exigindo padrões técnicos e urbanísticos inatingíveis, acabando por reservar as áreas nobres e providas de infraestrutura para o mercado imobiliário destinado às classes média e alta, ignorando, assim, as necessidades dos grupos menos favorecidos.

Desta forma, os moradores dos cortiços, vilas e demais habitações coletivas precárias são escamoteados, mantendo-se no regime de invisibilidade no decorrer dos anos. Além do interesse por parte do poder público de "mascarar" a existência de tais habitações, esta condição se solidifica por outros meios.

No caso da cidade de João Pessoa, por exemplo, a invisibilidade é reafirmada pela ausência de referência ao bairro Varadouro nos dados sobre demanda imobiliária e pesquisa de mercado oferecidos nas páginas eletrônicas do Sinduscon - Sindicato da Indústria da Construção Civil de João Pessoa e do CRECl - Conselho Regional de Corretores de Imóveis. Através da pesquisa de mercado, o Sinduscon define o valor do $\mathrm{m}^{2}$ de lançamentos imobiliários por bairro em João Pessoa, no período de novembro de 2013 a junho de 2014; porém, o bairro Varadouro sequer é citado. O CRECI levanta dados estatísticos do mercado imobiliário através da coleta de dados primários e secundários junto às imobiliárias, corretores, construtoras e incorporadoras, referentes tanto a imóveis ofertados quanto comercializados no período de janeiro a setembro de 2012; mais uma vez, o bairro não integra a pesquisa.

\footnotetext{
${ }^{3}$ Afastar-se para esquecer, afastar-se para não ver, afastar-se para se esconder... (PARIS, 2003, p. 09, tradução própria).
} 
As características físicas das HCPAs também são fortes fatores para a concretização da invisibilidade. A fachada, por exemplo, é um elemento indispensável para a visualização dessa condição. Ela marca a contradição exterior/interior e, no caso das habitações coletivas de aluguel, ao se apresentar aos olhares dos transeuntes, esconde o universo existente no interior do imóvel (figuras 03 a 08). Octavie Paris (2013), ao tratar da invisibilidade pelo viés da fachada, aponta a contradição exterior/interior ao resgatar o termo cotidiano de sentido figurado "pura fachada", quando se trata de alguém ou de alguma atitude: tudo está na aparência; o interior é vazio ou diferente.

Assim, a fachada aparece como um artifício que não sugere prenúncio, que não atrai a imaginação de como se configura a parte posterior da edificação (PARIS, 2013). O interior fica em segundo plano não só no imaginário dos transeuntes nas ruas, mas também na legislação municipal, cuja preocupação se restringe apenas à aparência das fachadas dos edifícios situados nas áreas centrais brasileiras. Através da fachada, inúmeros indícios revelam para os olhares atentos que a edificação se trata de uma habitação coletiva de aluguel. Um dos rastros identificados em algumas HCPAs é a má conservação de suas antigas fachadas e até mesmo a descaracterização de sua arquitetura, como se pode ver nas figuras 07 e 08.

Figuras 07 e 08: Exemplos de descaracterização da fachada de um casario da área central de João Pessoa, que funcionam como habitação coletiva precária de aluguel.

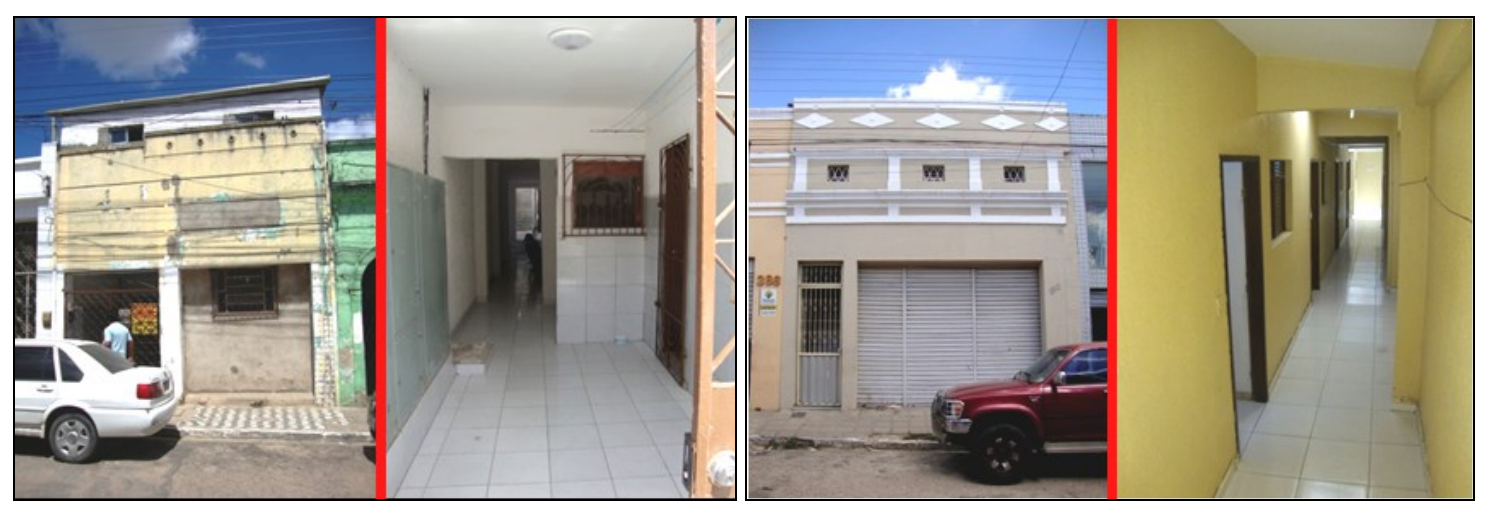

Fonte: Acervo pessoal, 2012/2014.

As movimentações através da porta, tida como um elemento mediador entre o exterior e o interior, o público e o privado, se apresentam como outro vestígio importante. Por meio dela, observam-se as idas e vindas, as entradas e saídas de distintas famílias e de um grande número de pessoas, o que numa habitação unifamiliar não é identificado ou, pelo menos, não é comum.

Outra indicação obtida nas fachadas de diversos exemplares de HCPAs é o amontoado de leitores de água e/ou luz, existente apenas quando os locadores individualizam esses serviços, fazendo com que cada locatário pague suas próprias contas (ver figura 09). Este indício não é tão frequente, tendo em vista que a individualização dos serviços de água e energia elétrica é 


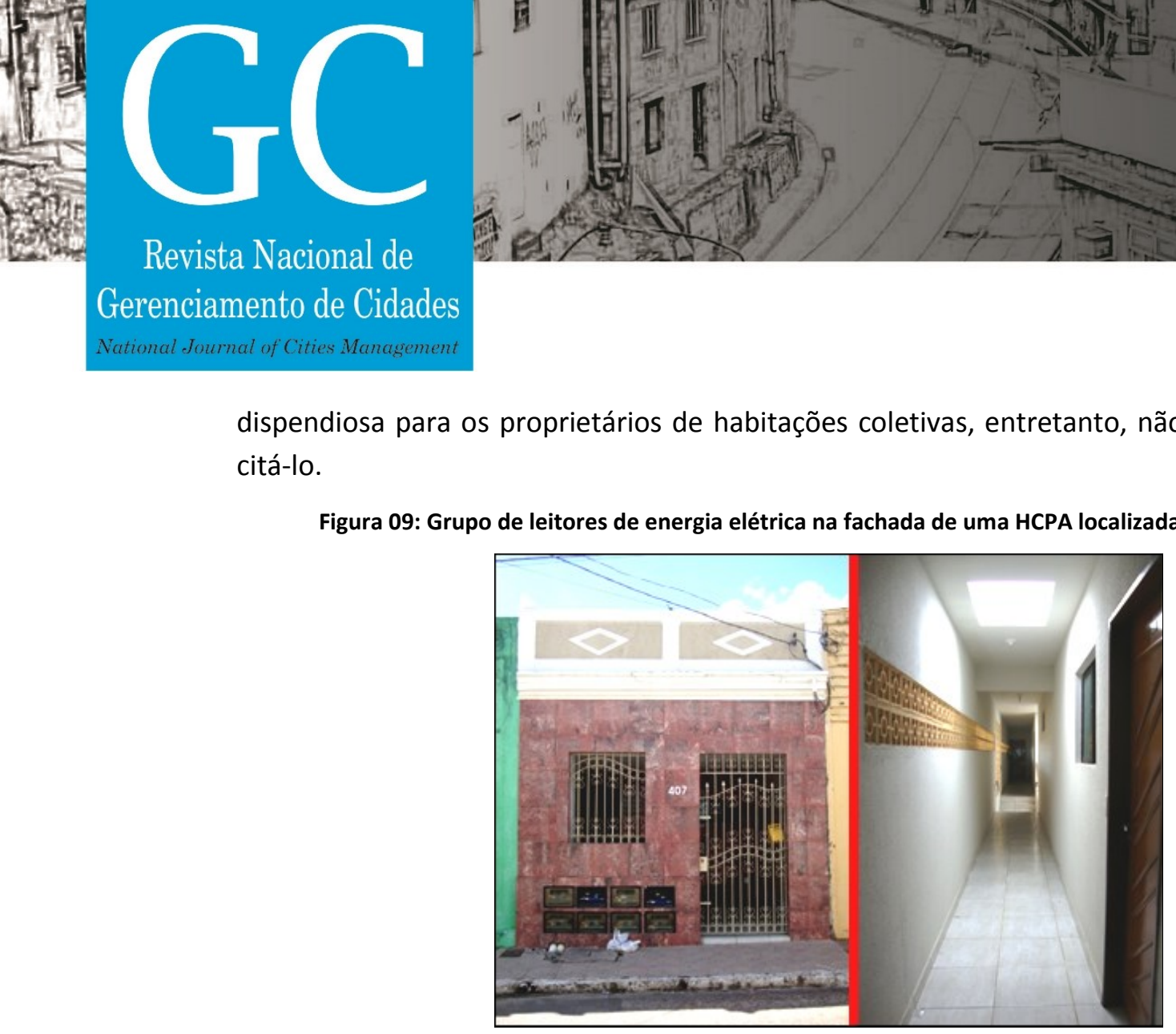

Fonte: Acervo pessoal, 2012/2014.

Por fim, foi identificado outro sinal: a divulgação de "quartos" disponíveis para locação através de placas improvisadas. Talvez esta seja a forma mais clara para identificação das habitações coletivas de aluguel. Além de permitirem identificar as residências multifamiliares, as placas de "aluga-se" dão pistas para decodificarmos a dinâmica socioeconômica da qual faz parte esse modo de morar.

Embora haja vários indícios para a identificação de tais habitações na paisagem urbana, bastante sutis para os olhares passageiros, as HCPAs prosseguem invisíveis, não apenas com a ajuda de sua aparência de residência unifamiliar (na maioria dos casos), mas também pela forma de acesso a elas, através do mercado informal. A informalidade exclui a presença de imobiliárias intermediando esse acesso, resultando na inexistência de dados sobre as transações imobiliárias na região em que as HCPAs estão inseridas e, consequentemente, na sua invisibilidade perante o mercado.

A precariedade das habitações, os conflitos provenientes da coletividade dos espaços, bem como a incerteza no que diz respeito à permanência nas HCPAs, resultam no individualismo acentuado característico deste modo de vida e não permitem, ou, no mínimo, dificultam a criação de um senso de comunidade entre os residentes, o que constitui mais um fator facilitador para a invisibilidade, desta vez social.

\section{CONSIDERAÇÕES FINAIS}

A pesquisa que se finda nesta ocasião decorreu da necessidade de apreensão do processo de (re)produção das invisibilizadas habitações coletivas de aluguel nas áreas centrais das cidades contemporâneas, que vão de encontro ao quadro de degradação e abandono de antigos 
como revitalização, requalificação, renovação, reabilitação, etc.), sob o argumento da ilegalidade de tal situação e da suposta oferta de habitações melhores na periferia urbana.

Evidencia-se assim, um vasto campo de conflitos e interesses por parte dos locadores, dos locatários, e por que não, do poder público. Como bem explana Miagusko (2008, p.128), "Iugar de pobreza e riqueza, de convivência dessa diversidade inter-classes que ilumina e oculta, que se apresenta em representações sociais e simbólicas, que condensa esse conflito, o Centro é o lugar contraditório dessa disputa, na maioria das vezes silenciosa".

Trata-se de um "terreno movediço", uma discussão complexa, permeada por diversos parênteses e reticências, onde a invisibilidade não pode ser lançada apenas como algo positivo ou negativo. Enfim, há muito que discutir nesse campo conflituoso e ainda tão obscuro.

Por fim, anseia-se que esta pesquisa incite novas investigações no campo da arquitetura e urbanismo, sobretudo no que se refere às políticas públicas habitacionais, alcançando, um dia, proposições de soluções que atendam a todos os agentes envolvidos no mercado imobiliário informal de forma equânime e justa.

\section{AGRADECIMENTO}

Agradecemos inicialmente aos moradores de vilas e cortiços do bairro do Varadouro, por nos permitirem adentrar em suas casas e conhecer um pouco de suas vidas, por compartilhar suas experiências e institivamente me ensinar tanto sobre a realidade. Somo gratos também à Coordenação de Aperfeiçoamento de Pessoal de Nível Superior - CAPES, pela bolsa que viabilizou a concretização desta pesquisa.

\section{REFERÊNCIAS}

ALFONSIN, Betânia de Moraes. Da invisibilidade à regularização fundiária: a trajetória legal da moradia de baixa renda em Porto Alegre - Século XX. 2000. Dissertação (Mestrado em Planejamento Urbano e Regional) - Faculdade de Arquitetura, Universidade Federal do Rio Grande do Sul, Porto Alegre, 2000.

; FERNANDES, Edésio. A lei e a ilegalidade na produção do espaço urbano. Belo Horizonte: Del Rey, 2003.

BLAY, Eva. Eu não tenho onde morar; vilas operárias na cidade de São Paulo. São Paulo: Nobel, 1985.

BONDUKI, Nabil (Org.). Habitat: as práticas bem sucedidas em habitação, meio ambiente e gestão urbana nas cidades brasileiras. 2ª ed. São Paulo: Studio Nobel, 1997.

Origens da habitação social no Brasil: arquitetura moderna, lei do inquilinato e difusão da casa própria. 4ạ ed. São Paulo: Estação Liberdade, 2004.

CANDIDO, Malta Campos; PEREIRA José Eduardo Borba. Da segregação à diversidade: moradia e requalificação urbana na área central de São Paulo. Cadernos de Pós-Graduação em Arquitetura e Urbanismo, São Paulo, v.5, n.1, 2005, p. 01-24.

DAVIS, Mike. Planeta Favela. Tradução Beatriz Medina. São Paulo: Boitempo, 2006. 
